\title{
Perahu Dalam Beberapa Prasasti Indonesia
}

\section{Rita Margaretha Setianingsih}

Keywords: ship, boat, maritime, archaeology, inscription

\section{How to Cite:}

Setianingsih, R. Margaretha (1993). Perahu Dalam Beberapa Prasasti

Indonesia. Berkala Arkeologi, 13(1), 10-21. https:/ / doi.org/10.30883/jba.v13i1.562

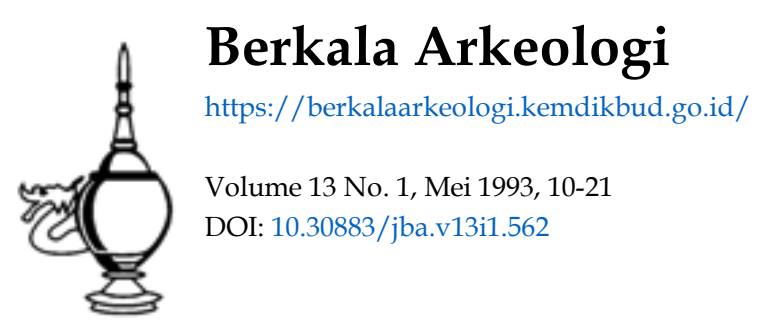




\section{PERAHU DALAM BEBERAPA PRASASTI INDONESIA}

Oleh: Rita Margaretha Setianingsih

Indonesla sebagal sebuah negara yang sebaglan besar dart luas permukaannya merupakan perairan, mengenal berbagal jenis - Lat transportasl alr Keahlian membuat alat transportasl itu dimiliki wieh masyarakat yang berdiam di pantal dan juga pada masyarakat yang hidup di pedalaman. Kita kenal istllah "Janggolan" yang nerupakan alat pengangkutan barang dagangan antar pulau sihasllkan oleh penduduk pulau Madura, lambo yang dihasllkan rasyarakat Bugis-Makassar, atau jukung banyak digunakan untuk menangkap Ikan oleh masyarakat pantal di pulau Ball. Selanjutnya kita ketahul pula adanya londel yang digunakan di danau Tondano. Sulawesi Utara, maupun solu di danau Toba, Sumatera Utara.

Keberadaan Jenis-jenis alat ransportasi air itu pada masa lampau juga dapat kita ketahul darl beberapa tinggalan perahu yang belakangan int bermunculan dan telah diteliti oleh tim dari Pusat Penelitian Arkeologl Nasional. Seperti di Sambirejo dan Kolam Pinisi (keduanya di Palembang). Bukdt Jakas di Pulau Bintan (Rlau) serta di Paya Pastr, Medan. KIta dapat Juga merujuk pada tinggalan masa prasejarah yang berupa wadah mayat di Kallmantan dengan bentuk-bentuk perahu bangau (banawa ungang dalam bahasa Dayak) dan perahu ular alr (banawa bulau) (Soejono. 1987: 2). Adapur: darl masa budaya yang dipengaruht Mindu-Buddha (masa klastk indonesla), keberadaannya ditunjukkan dalam pelbagai naskah, relief candi (seperti yang ditemul di candi Borobudur) serta prasast.

Dalam tulisan singkat inl, penulis mencoba untuk risemanfaatkan prasastl sebagal salah satu sumber informasl tentang keberadaan perahu di masa lampau. Kenyataannya, darl hasil pembacaan dan pembahasan oieh penelltl asing maupun bangsa sendirt terhadap beberapa prasastl yang dalam kesempatan ini digunakan sebagal bahan penulisan, dapat diketahul adanya beberapa jenls berlkut fungsi perahu bahkan keberadaan petugas yang mengurusinya. 


\section{I}

Bertkut Int adalah sebaglan darl prasast1- prasast1 Indonesla yang digunakan oebagal sumber penulioan, masing-masing adalah :

\section{Praneti Eedukno Buljt}

Tempat temuan : Kedukan Bukd, di tepl sungal Tatang, Palembang. Sumatera Selatan

Angka tahun : $605 \mathrm{C} / 783 \mathrm{M}$

Nama raja : Dapunta Htyang

Keterangan terdirt dart sepuluh barls tulisan berhuruf Pallawa, bertiahasa Melayu Kuna dan dipahatkan pada batu andesit berbentuk bulat

IsI Dapunta Htyang yang berangkat darı Minảnga Tamwan dengan membawa tentara datang di Mata Yap. Setelah menaklụkkan beberapa daerah kemudian membangun sebuah kota bernama Srtwijaya

Acuan Ph S van Ronkel (1924: 12-21), Boechart (1986: 35), N J Krom (1926: 76) dan Juga G Coedes - L Ch Damals (1989: 53)

Baglan kuncl ".... Dapunta hlyang nâytk di sāmuau maialap siddhayâtra .....

Terjemahan "....... sit baginda naik perahu/kapal untuk mencarl kesaktlan ...."

\section{Prasasti ramalargan/Eelngen}

Tempat temuan

Angka tahun : $959 \mathrm{C} / 1037 \mathrm{M}$

Nama raja Alrlangga

Keterangan berhuruf dan berbahasa Jawa Kuna yang dipahatken pada batu andesit

IsI pembangunan bendungan untuk menghindar banjlr di Warlngin Sapta oleh Alrlangga sekaligus penetapan desa Kamalagyan sebagal perdikan dengan tugas menjaga dan memelihara bendungan tersebut

Acuan : JA Brandes - Krom (1913: 135) dan Sutjlpto (1858)

Baglan kunc1 . "... Vkang bar̃awan amattú hïltnyarilor kapwata 
silkhamanah ikang maparahu samanghulu marialap bhanda ri huyung galuh ..."

Tejemahan : "... aliran sungal ke arah utara dan semuanya senang berperahu mengambll barang-barang d1 Ujung Galuh ..."

\section{Prasasti Ferry}

Tempat temuan: dukuh Pelem. desa Temon, kecamatan Trowulan. Mojokerto, Jawa Tymur

Angka tahun : $1280 \mathrm{G} / 1358 \mathrm{M}$

Nama raja

Keterangan

Isi

Dyaḷ̣ Çrí Hayārn Wuruk

terpahat di atas lima lempengan tembaga. berhuruf dan berbahasa Jawa Kuna

dafitar nama-nama desa di seluruh pulau Jawa yang mendapat kewajlban untuk menyeberangkan penduduk dan memperlancar perdagangan

Acuan : T G Th Plgeaud (1960: 110), M.M.Soekarto K.Atmodjo (1979: 70 dan 72)

Baglan kuncl : "....kapangkwa dentkang anämbangt sayawadwīpamaṇdala. makā nuṣa, i tĕmon. ....." "....l kémbu. i wulayu. sarwwe, tka ta kabeh nadititrapradeça. sthānanya ng anāmbangi sayawa-dwipa ....."

Terjemahan : "..supaya disimpan oleh semua petugas penambangan di seluruh Pulau Jawa, nusa, temon ..." "... kembu. wulayu, Itulah semua desa-desa di tepl sungal. tempat penambangan atau penyeberangan di seluruh pulau ..."

\section{Prasasti Ayam Těas I}

Tempat temuan: Purworejo, Jawa Tengah

Angka Tahun : 822 C / J Januarl $901 \mathrm{M}$

Nama raja : Çrī Mahārāja Rake Watukura Dyah.

Dharmodaya Mahasambu

Keterangan : terpahat di atas lempengan tembaga berukuran $25 \mathrm{~cm} \times 9 \mathrm{~cm}, 9$ barts di baglan depan dan 6 barts di baglan belakang dengan 
IsI

Acuan

Bagtan kuncl

Terjemahan

5. Prasanti tenpa

Tempat temuan

Angka tahun

Nama raja

Keterangan

Is1

Acuan

Baglan kuncl

Terjemahan menggunakan huruf dan bahasa Jawa Kuna

peresmlan desa Ayam Teas menjadi sima

WF Stutterhelm (1938: 121-122); L.Ch. Damals (EEI III)

".. hana ayam téas atapa amasunghara 3 saparahu kabua maku ngalana tundan

: "..semuanya dibawa dengan tiga perahu dengan menggunakan gandengan (semacam tug boat)

\section{nama}

ditulis di atas lempengan tembaga dengan menggunakan huruf dan bahasa Jawa Kuna

: menyebutkar nama Wimalacrama dan beberapa jenis perahu

J L A Brandes (1913: 245)

"... panahes panawa kalima tundan, parahu pakbowan sawyi kapat tundan, parahu jurag 5. parahu panggagaran 5. parahu pawallari 5, parahu pangngayan 5. ...."

"... perahu penawa dengan 5 gandengan, sebuah perahu untuk mengangkut hasll kebun dengan 4 gandengan perahu Jurag 5 , perahu panggaran 5, perahu pedagang 5 , perahu panggayan 5 ..."

6. Pracasti Teleng

Tempat temuan : tepl sungal Bangunan Solo dekat Wonogiri

Angka tahun : : 825 C/903 M

Keterangan : berhuruf dan berbahasa Jawa Kuna

Nama raja

Isi Çrĩ Dhannodaya Mahāsambhu

Maharaja Balitung melaksanakan kaul dart raja yang dimakamkan di Satassrengga untuk membuat pangkalan di tept sungal Solo sebagai tempat tambangan bagl perahu yang menghubungkan kedua tepinya. menalkkan dan menurunkan barang serta penumpang. 
Penye berangan tersebut tanpa dipungut blaya, oleh karena itu Desa Telang, Mahe dan Paparahuan dijadikan sima.

Acuan : WF Stutterhelm ( 1934: 275 ), Himansu Bhusan Sarkar (1972)

Baglan kuncl : "...umentassakna sang mahawān prattdina ....."

Terjemahan : "... menyeberangkan orang dllakukan tlap har1 ....."

\section{Prasasti Kintamani/Tulurbigu}

Tempat temuan: Menu Pura Tulukblyu (Pura Batur Kanginan), Bat ur, Kıntamanı, Banglı, Balı

Angka tahun : 933 C. 1103 C dan 1306 C

Nama raja

Keterangan

Is1

Acuan

Dharmodayana Jayapangus dan Wijaya Rājasa

terdiri atas sekelompok lempengan tembaga yang ditulisi dalam huruf dan bahasa Jawa Kuna

: menyebutkan nama Er Hawang dan Bhatāra di Tulukblyu

Atmodjo (1977: 18)

Baglan kuncl : "....kahadargangalop kayu agedai, salwt raning kayu it thäninya, mapakna gaweyèn parahu, kaywanting mangrajakāya ...."

Terjemahan : "... mengambll kayu dart penduduk desa dan dibuat perahu sebagal kewajlban bagl/untuk raja ..."

\section{Prasasti Sambiran}

Tempat temiuan : -.. Angka tahun : Nama raja Keterangan IsI

$844 \mathrm{C} / 922 \mathrm{M}$

\section{Anak Wungsu}

berhuruf dan berbahasa Jawa Kuna

pembebasan dart pajak bagı desa Julah karena dirusak musuh dan penduduknya banyak yang ditawan. Selaln dibert ijln mendirkan meru di tempat kuilnya, desa Julah Juga diperbolehkan menawan perahu yang terdampar untuk 

Acuan : R Corto (1954), M.M.Sockarto K Atmodjo (1979. 69)

Bagtan kuncl : "....me yorado taban kararg dithe parahus. lañcang. Juburg. colatea anat banwa katahwan duya kajadyan wridh kerwāina ma matahu ake. pyanetangina bahtura di bhatara punía ryang...."

".... yan hana banyaga sateng sabrang forg. bahitra, comundeck 1 manāsa ....."

Terjemahan : "... dan kalau ada karang di sana, perahu. lancang. Jukung, talaka, penduduk desa merampas perahu dan sebagalnya itu dipergunakan sebagal persembahan. Beritahukanlah hal itu kepadaku. Persembahan eebagal tanda baktı kekadapan bhatara Punta Hyang (leluhur) ..."

"..... Kalau ada saudagar dart luar yang menggunakan perahu (jung), bahitra datang berlabuh di Minasa ..."

\section{Promatd Pura Koben A}

Tempat temuan : Pura Kehen, Bangll. Ball

Angka tahun : $1126 \mathrm{C}$

Nama raja - Anak Wungsu dan Bhatara Guns Sn Adikunuketana

Keterangan : sekelompok lempengan tembaga dengan tulisan berhuruf Kaw dalam bahasa Ball Kuna maupun Jawa Kuna

IoI

pembuatan bangunan pertapaan di Hyang Karmana sertamenyebulkan Bangll sebagal karaman

Acuan : R.Gorts (1954), M.M.Sockarto K Atroodjo (1977:20) dan P.V.van Callenfelo (1926:56)

Baglankund : "...mathap bantllar larioang parake nargroputh ara ...."

Terjemahan 
Darl beberapa buah prasast tersebut di atas masing-masing berasal atau ditemukan di Sumatera, Jawe dan Ball terlihat adanya beberapa jenis perahu serta slnonim dar kata perahu. Stnonim kata yang dimaksudkan adalah :

\section{a. āmontu}

Dalarn prasastl Kedukan Bukdt ktta ketahul adanya penggunaan sämwau sebagal sarana transportasl alr untuk mengangkut bala tentara. Dapat diduga bahwa tentunya sāmwau itu memillkl ukuran yang cukup besar Walaupun sebaglan ahli berpendapat bahwa kata sāmwau dapat langsung diterjemahkan dengan perahu. tampaknya tidak salah apablla kata itupun didekati sebagal kata sampan. Kata sampan itu sendirt menimbulkan cukup banyak perbantahan dalarn mengartikannya. Sebaglan menyebutkan bahwa kata sampan berasal dart bahasa Jawa dan Melayu, sedangkan lalnnya mengatakan bahwa kata sampan itu berasal dart bahasa Cina sanpan yang artinya tiga papan. Kata sampan Itu sendirl cukup populer digunakan untuk menggambarkan bargas (tongkang) t/dak saja di Cina melainkan Juga di Jepang dan di disebaglan kawasan Asla Tenggara secara umum. Suatu pendapat lain Juga menyatakan bahwa kata sampan icblh dekat ke bahasa penduduk asll Amertka Latin, clampane atau champan, servertl keterangan yang diperoleh darl sumber-sumber abad ke 15 dan ke 16 (Noel Pert. 1919: 13-19). Bagaimanapun Juga, semuanya memilki artl perahu, alat transportasl alr.

\section{b. laũcang}

Kata Ini memillkd art sebagal perahu yang menggunakan layar sebagal tenaga penggeraknya dan dapat melaju dengan Incahnya sehingga dahulu banyak digunakan untuk keperluan perang. Keltncahannya di alr itu pula yang menyebabkan pada sekdtar abad ke 16-17. Jenis Inl digunakan sebagal perahu pos oieh Belanda di sekitar Laut Jawa.

c. Jaktong

Jingga saat InI penggunaan kata Jukung sangat dikenal, 
khususnya pada masyarakat pantal yang menggurakarnya untuk keperluan penangkapan ikan. Secara flokk, Jukung (atau fongkong) adalah perahu yang dibuat dart cebatang kayu yang beear dtmana baglan tengahnya dllubang untuk menghasllkan ruangan, dan dilengkapl dengan cadik untuk membantu kesetmbangannya di atas permukaan als.

\section{d. Bantere}

Tentunya kata bahtera yang sekarang dikenal untuk menggambarkan perahu berukuran besar yang mengangkut barang maupun penumpang di lautan berasal dart kata bahitra.

Darl prasastl pula kita ketahul bahwa masyarakat Indonesia kuna, di Jawa khususnya. menggunakan perahu sebagal sarana ransportaol melewatl sungal darl satu desa ke desa lainnya. Sepert yang dicantumkan di dalam prasastı Ferry, mereka anāmbangı (menyeberang dengan perahu atau rakdt? - tambang) dar desa ke desa lain di seluruh pulau Jawa ("... sayawadwtpamandala ... "). Keglatan menyeberangkan orang itu dilakukan setlap hari ("...uměntassakna sang mahawän pratudina ....") pada desa-desa yang terletak di tepl sungal (" .... nadítira pradeca ..... "). Dikatakan pula bahwa orang yang diseberangkan itu tidak boleh dikenakan blaya ("...salürnikanang Gartasakanya tan pintōra atah upahan ...').

Dan untuk mengawasl serta mengurusi tempat-tempat penyeberangan Itu ada petugasnya, yaknl manambani, yang merupakan salah satu jabatan darl mangllala drawya hafl (petugas yang berhubu-ngan dengan soal penarkan luran, pajak dan lain-lainnya) (Soekarto. 1977: 57). Petugas tersebut karena thak mendapat gaj! tetap. juga tidak memilikd daerah lungguh. masuk ke beberapa desa untuk meminta/menark sejumlah uang tetapi thdak diperbolehkan masuk ke desa yang telah dijadkan sima atau swatantrā.

Perahu tidak hanya digunakan untuk mengangkut penumpang aja melainikan mengangkut pula barang-banang (dagangan) ("....maparahu samanghulu maralap bhanda r..."." Masyarkat menggunakannya untuk mengangkut hasll buml dar kebun (parahu pakbowan) ilhat catatan I), mencarl lkari (parahu jurag. serta untuk kepertuan dagang parahu pawatjaan dan parabu sajunagan!.

Pada kumang lebth abad ke 10 di pulau Ball, diketahul pula 
bahwa perahu juga digunakan sebagal persembahan yang merupakan tanda baktı kepada Bhatara Punta Hyang ('... parahu, lañeang. jukung, talaka anak banwa katahwar diya kajadyan

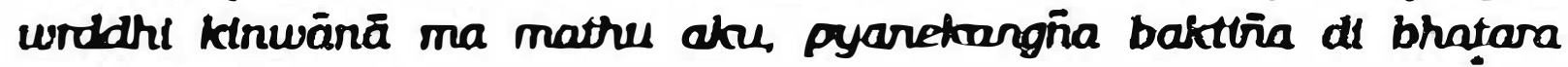
purta hyang ....." ")

\section{IV}

Demikian secara singkat mengenal perahu sepert yang tercantum dalam beberapa prasasti. Cukup banyak kegunaan perahu bagi kehidupan masyarakat pada Jaman dulu. itu harus dlakul. Selain berfungsl sebagal sarana pengangkutan manusla. alat untuk mencari Ikan, perahu digunakan pula sebagal alat bantu dalam pengangkutan hasll kebun, barang dagangan serta perang.

Sebagal penutup, diharapkan bahwa tulisan InI dapat menjadi alat pemacu untuk penelitian yang leblh mendalam mengingat sumber yang digunakan hanya merupakan sebaglan kecll darl data yang ada. Bagalmanapun. Indonesla sebagal suatu kawasan kepulauan terbesar di dunla dengan masyarakat maritimnya sangat memerlukan keterangan yang lengkap tentang gambaran se jarah kehidupan yang berhubungan dengan peralran di masa laiu. Prosasti sebagal salah satu sumber. salah satu benda arkeologls - yang cukup banyak dijumpal - diharapkan mampu menceritakan sejarahnya.

\section{Catatan:}

1. Antolnette Barett Jones dalam bukunya Early Tenth Century Java From The Inscriptions (1984) mengartikan parahu pakbowan sebagal perahu pengangkut kerbau. Hal int tampaknya terjadi karena kesalahan didalam pembacaan prasastl. Bukan pakbowan (kbo = kerbau) melalnkan pakbwan (=kebun). Apalagi blla dilngat bahwa untuk keperluan mengangkut seekor kerbau misalnya. Jelas diperlukan sebuah perahu yang benukuran cúkup besar, setidak-tidaknya perahu dengan kapasitas untuk 10 orang. Berbeda sekall halnya dengan perahu yang digunakan untuk transportasi petani ke kebunnya yang sekaligus digunakan untuk membawa puiang hasll tanamannyz - yang hingga saat ini masih urnum dijumpal di hampir seluruh wllayah tanah alr - dengan ukuran yang 
rolatif keell Dapasitas cekdtor 3 - 5 orang anja). Tetapl tentunya hal inl masth periu ditelaah leblh lanjut. 


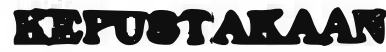

Barret Jones, Antolnette. 1884. Farty Tenth Contory Java From The Inecriptlone. Dordrecht - Molland/ Cinnamin-con USA: Forts Publications.

Boechart. 1977. Manfaat Stud1 Bahasa dan Sastra Jawa Kura Duryau Dart segt Sejarah dan Arkeologt, Majulah Arkeolort, Nomor 1, hal. 5 - 30.

- 1985/1886. Tranati Eolotal Musoum Nacional, Jilld I. Jakarta: Proyek Pengembangan Museum Nasional.

1986. New Investlgation The Kedukan Buktt Inscription, Untuk Bapal Gura. Porsembahan Para Murid Untuk Memperingati Uala Gonap 80 Tahun Jakarta : Pusat Penelitian Arkeologi Nastonal, hal. 3 - 56.

Brandes, J L A - Krom. 1913. OudJlavaarscte Corkonden, VBO IT Damais, L Ch. ESI III dan ERI IV.

Gorts, R 1954. Preantl Ball I dan II. Jakarta: Lembaga Bahasa dan Budaya.

Coedes. G - Damals, L Ch. 1989. Lodatunn 8riwhaya. Ponelitian Tontang 8xiwijaya Jakarta: Pusat Penelitian Arkeologi Naslonal - Ecole Francalse d 'Extreme-Orlent.

Krom, N.J. 1926 Findoo-Javanneche Geschledenis s'Gravenhage: Martinus Nijhoff .

Noel . Pert. 1919. A Propus Du Mot Sampan BEPEO, TOME ZR. 1919. Hanol, hal. 13-19.

Pigeaud. T G Th. 12960 Java In The 14th Contury. A Study in Caltural Filstory s'Gravenhage: Martinus Nijhoff.

Ronkel. Ph S van. 1924 A Prellmenary Note Concerning Two Oid inscriptions In Palembang, Acta Orientalia, 2, hal. 12-21.

Suekarto K Atmodifo. M.M. 1979. Strultur Mangamint Jiswa Bana Bada Jaman Mataram Mlndu Dan Majapahi: Yogyaktarta: Pusat Penelitian dan Studi Pedesaan. IGM.

1977. Laporan Penelitian Eplyrafi Balt Tahas ${ }^{\circ}$ Berita Ponelitian Arkeologi Nomor 1 Jakarta : Pusat Penelltian Arkeologi Nastonal.

Soejono. 1987. Perahu Sebagat Bentuk Wadah Penguburan Prasejanah Eomtnar Bobahnrian Acoan Jakarta: Museum Nastonal.

Sutjtpto WIrjooceparto, 1958 Apa Sebabnya Kedirl Munai Dalim 
Sejarah Lapeoran IIE I. Jakarta: Lombaga Ilmu Pengetahuan Indonesla.

Steln Cellenfils, P.V. van. 1026. Aptgraphia Balioa I, V:O 4.

Stutterheim, W F. 1934. Een vry over set veer te Wanagut in 903 AD. Tia 74. hol. 269-295.

. 1938. JBQ, hal. $121-122$.

nm Penyrusun Kamus. 1990. Knmu Bosar Babase Indonesta. Jakarta : Balal Pustaka. 